\title{
CULTURAS DO TRABALHO, EDUCAÇÃO E PRODUÇÃO DA EXISTÊNCIA: ENTRE QUILOMBOLAS, CASTANHEIROS E SERINGUEIROS.
}

\author{
CULTURES OF WORK, EDUCATION AND PRODUCTION OF EXISTENCE: \\ BETWEEN QUILOMBOLAS, NUT GATHERERS AND RUBBER TAPPERS.
}

Lia Tiriba ${ }^{1}$

William Kennedy do Amaral Souza ${ }^{2}$

\begin{abstract}
RESUMO
O propósito deste artigo é refletir sobre modos de vida em povos e comunidades tradicionais, trazendo evidências empíricas dos nexos entre trabalho-educação e economia e cultura. Tendo o materialismo histórico como referência teórico-metodológica, perguntamo-nos: mediados pelo trabalho, que relações mulheres e homens estabelecem com a natureza? Quais são os costumes e normas de convivência que orientam a vida em comunidade? Quais são as mediações do capital na conformação das culturas do trabalho? A pesquisa foi realizada no Vale do Guaporé, em Rondônia, junto às comunidades de Forte Príncipe da Beira e Santa Fé e aquelas que se situam na Reserva Extrativista do Rio Cautário. Os procedimentos consistiram em entrevistas e rodas de conversa. A pesquisa evidencia que as comunidades tradicionais sofrem com as ações destrutivas do capital e que a afirmação de seus modos de vida constitui elemento de estruturação de sua resistência frente às dificuldades da vida.
\end{abstract}

Palavras-chave: povos e comunidades tradicionais, cultura do trabalho, modos de vida.

\begin{abstract}
The purpose of this article is to reflect on the ways of life of traditional peoples and communities, bringing evidence of the links between work-education and economy and culture. Having historical materialism as a theoretical-methodological reference, we ask ourselves: mediated by work, what relationships women and men establish with nature? What are the customs and norms of coexistence that guide community life? What are the mediations of capital in the configuration of work cultures? The survey was conducted in the Vale do Guaporé, in Rondônia, with the Communities of Forte Príncipe da Beira and Santa Fé and those located in the Rio Cautário Extractive Reserve. The methodology consisted of interviews and conversation circles. The research shows that traditional communities suffer from the destructive actions of capital. It also shows that the affirmation of their ways of life constitutes an element of structuring their resistance in the face of life's difficulties.
\end{abstract}

Keywords: traditional peoples and communities, economy and culture, modes of life.

\footnotetext{
Doutora em Ciências Políticas e Sociologia (Programa de Sociologia Econômica e do Trabalho) pela Universidade Complutense de Madrid. Professora do Programa de Pós-Graduação em Educação da Universidade Federal Fluminense (UFF-RJ).

2 Doutor em Educação pela Universidade Federal Fluminense (UFF-RJ). Professor do Instituto Federal de Rondônia (IFRO-RO). Membro do grupo Nómade, pesquisador da linha Trabalho-Educação, Economia e Cultura na Amazônia.
} 


\section{INTRODUÇÃO (OU ALGUNS PONTOS DE PARTIDA)}

Em seu livro Amazônia: riqueza, degradação e saque, cuja capa traz a foto de um trem carregado de minério de ferro da Vale S/A na Estrada de Ferro Carajás, no Maranhão, Gilberto Marques (2019) lembra que Jair Bolsonaro (PSL), durante campanha em 2018, afirmou que em seu governo não haveria mais nenhum centímetro de terra para os indígenas. De acordo com o Observatório do Clima, entre junho e setembro de 2018, a taxa de desmatamento subiu $36 \%$ na Amazônia. Nesses quatro meses, foram $2.414 \mathrm{~km}^{2}$ de floresta derrubada, comparados a 1.769 $\mathrm{km}^{2}$ no mesmo intervalo do ano anterior. Os perigos para a humanidade, como as mudanças climáticas, a poluição ambiental e a devastação do planeta, decorrem tanto do saque das riquezas minerais e naturais consideradas em sua biodiversidade quanto do próprio aquecimento global. E, como afirmou Fearnside, a Amazônia "não é apenas uma vítima do aquecimento global, é também uma fonte de emissões antropogênicas por desmatamento, degradação florestal por exploração madeireira e incêndios e emissões de represas hidrelétricas" (2018, [n.p.]). Assim, não por acaso a Floresta Amazônica entrou em chamas, em agosto de 2019, tornando-se a Pacha Mama manchete na imprensa internacional.

Em sua obra 17 contradições e o fim do capitalismo, Harvey (2016) analisa a crise atual do capitalismo no século 21, a qual - assim como todas as suas crises - é essencial para sua reprodução. Sobre "contradições perigosas", tanto para o capital, como para a humanidade, o autor ressalta a relação do capital com a natureza que, em nome de um crescimento exponencial infinito do próprio capitalismo, "transformou a questão ambiental em um grande negócio. As tecnologias ambientais são cotadas a valores altíssimos nas bolsas de valores" (HARVEY, 2016, p. 231).

Sendo o ecossistema submetido à unidade contraditória entre capital e natureza, sofre o planeta Terra, sofrem as populações urbanas e rurais e, em particular, os povos e comunidades tradicionais com o desmatamento, com a construção de estradas, hidrelétricas e barragens, com a monocultura e a contaminação dos rios e das florestas com resíduos de pesticidas, fertilizantes e uma gama de agrotóxicos.

Desde a chegada dos europeus ao Brasil, a chamada Amazônia Legal, que ocupa 61\% do território brasileiro, tem sido um espaço no qual se realizam saques de bens naturais para acumulação das corporações capitalistas, deixando um prejuízo ecológico gigantesco, além de um rastro de violência contra seus habitantes. Têm sido o Estado, as organizações multilaterais e supranacionais os principais guardiões das políticas que promovem, conforme Ioris, "A produção da pobreza e a pobreza da produção na Amazônia" (2015, p. 180), privilegiando a apropriação privada dos "homens de negócio", em detrimento da preservação do que é (ou deveria ser) "comum" à humanidade, ou seja, os recursos naturais, os espaços públicos, os conhecimentos historicamente acumulados, o direito ao trabalho, à moradia, à saúde e à educação, entre outros (DARDOT; LAVAL, 2017).

Como categoria analítica e ao mesmo tempo política, são considerados "povos e comunidades tradicionais" indígenas, quilombolas, seringueiros, castanheiros, quebradeiras de coco de babaçu, faxinais, sertanejos, caipiras, sitiantes-campeiros, fundo de pasto, vaqueiros, ribeirinhos, pescadores artesanais, caiçaras, varjeiros, jangadeiros, marisqueiros, pantaneiros, caatingueiros, vazanteiros, geraizeiros e chapadeiros (CRUZ apud CALDART, 2012). De acordo com o Decreto Presidencial n. ${ }^{\circ}$ 6.040/2007, são

\footnotetext{
grupos culturalmente diferenciados e que se reconhecem como tais, que possuem formas próprias de organização social, que ocupam e usam territórios e recursos naturais como condição para sua reprodução cultural, social, religiosa, ancestral e econômica, utilizando conhecimentos, inovações e práticas gerados e transmitidos pela tradição (BRASIL, 2007, [n.p.]).
} 
Entre eles, podemos incluir os povos andinos na Bolívia, no Peru, no Equador, na Colômbia, no Chile e na Venezuela, onde sobressaem índios(as) e mestiços(as). Para Solano e Lazarini, nas economias comunitárias das sociedades andinas e da Mesoamérica "o sujeito transcendental e principal é a comunidade, integrada a partir do trabalho coletivo e da propriedade comunitária, articulados em equilíbrio e respeito à natureza como sujeito participante, vivo" (apud CATTANI; CORAGGIO; LAVILLE, 2009, p. 121). Ou, como assinalou a Comandante Kéli, do Exército Zapatista de Libertação Nacional (México) e que se tornou referência para Rosset, "para os povos indígenas, camponeses e rurais, a terra e o território não são apenas fontes de trabalho e de alimentos; são também cultura, comunidade, história, ancestralidade, sonhos, futuro, vida e mãe natureza" (apud CATTANI; CORAGGIO; LAVILLE, 2009, p. 1).

Como Thompson (1981), entendemos a história como processo estruturado, o que requer a análise dos nexos entre economia e cultura, considerando o conjunto das relações sociais, inclusive daquelas que configuram modos de produção da existência subordinados ao modo de produção capitalista. A história não é uma sucessão linear de modos de produção movidos por "leis fundamentais", não sendo possível reduzir as "formações econômico-sociais a uma simples escada que todas as sociedades humanas sobem, degrau por degrau" (HOBSBAWM, 1991, p. 59). Mais que relíquias do passado, são modos de produção que permanecem vivos na história. Assim "devemos ser contrários à filosofia evolucionista, historicista e racionalista", que elege o "[...] progresso [...] como o único caminho para a humanidade" (MARIÁTEGUI, 2011, p. 144). Como ele, acreditamos que, se fortalecida a organização econômica coletiva, os "povos da economia rudimentar" não precisarão "sofrer a longa evolução pela qual passaram outros povos" (2011, p. 144).

Historicamente, à margem da produção de riquezas, homens e mulheres reagem e se organizam em torno de uma pauta de reivindicações, entre elas a defesa de seus territórios e o reconhecimento do direito de decidir sobre seus modos de produzir a vida. Por isso, como alerta Williams (2011), quando falamos de hegemonia (que não é um conceito estático), é preciso considerar o que está "fora" do modo dominante. Isso porque

Nenhum modo de produção e, portanto, nenhuma sociedade dominante ou ordem da sociedade e, destarte, nenhuma cultura dominante pode esgotar toda gama de prática humana e da intenção humana (essa gama não é o inventário de alguma "natureza humana" original, mas ao contrário, é aquela gama extraordinária de variações práticas e imaginadas pelas quais seres humanos se veem como capazes) (2011, p. 59).

Nesse texto, para dar visibilidade a essas "variações e práticas imaginadas" (WILLIAMS, 2011, p. 50), articulamos duas pesquisas em andamento (TIRIBA, 2018 e SOUZA, 2018) que se complementam ${ }^{3}$ e são realizadas no Vale do Guaporé, em Rondônia, nas Comunidades de Remanescentes Quilombolas - Forte Príncipe da Beira e Santa Fé - e naquelas que se situam no interior da Reserva Extrativista (RESEX) do Rio Cautário ${ }^{4}$. Com a intenção de apresentar elementos materiais e simbólicos de culturas do trabalho em que homens e mulheres,

\footnotetext{
3 A pesquisa contou com a participação de Victor Ferreira Raposo, bolsista de Iniciação Científica (FAPERJ). O trabalho de campo teve o apoio da Fundação de Amparo ao Desenvolvimento das Ações Científicas e Tecnológicas e à Pesquisa do Estado de Rondônia (FAPERO), por meio da Chamada FAPERO nº . 010/2016.

${ }^{4}$ Reservas Extrativistas (RESEX) são espaços territoriais protegidos cujo objetivo é a proteção dos meios de vida e a cultura de populações tradicionais, bem como assegurar o uso sustentável dos recursos naturais da área. $\mathrm{O}$ sustento dessas populações se baseia no extrativismo e, de modo complementar, na agricultura de subsistência e na criação de animais de pequeno porte. A área das RESEX pertence ao domínio do poder público, com uso concedido às populações extrativistas tradicionais.
} 
diferentemente da lógica do capital, produzem a vida associativamente, apresentamos a seguir os resultados da imersão no campo de estudo, em setembro de $2018^{5}$.

Tendo o materialismo histórico como referencial teórico-metodológico e com abordagem qualitativa, os procedimentos de pesquisa foram observação das práticas cotidianas, entrevistas semiestruturadas e rodas de conversa. Perguntamo-nos: mediados pelo trabalho, que relações mulheres e homens estabelecem com a natureza? Como se materializa a cultura do trabalho? Quais são as formas de associatividade? Quais são os costumes e as normas de convivência que orientam a vida em comunidade? Em que medida os processos escolares e não escolares contribuem para manterem vivas as práticas sociais e os saberes tradicionais? Quais são as mediações do capital na conformação dos modos de vida? Partimos do pressuposto de que, tecidas por fios (in)visíveis de cor de pele, gênero, etnia e geração, entre outros, essas culturas do trabalho corroboram a construção de sociabilidades fundadas na lógica da reprodução ampliada da vida, e não do capital.

\section{PARA ALÉM DO VALE DO GUAPORÉ "VISTO DE CIMA": A EXPANSÃO CAPITALISTA}

Sobre as maneiras de interpretar a realidade, Canclini afirma que "o antropólogo chega à cidade a pé, o sociólogo de carro e pela pista principal, o comunicólogo de avião. Cada um registra o que pode, constrói uma visão diferente e, portanto, parcial” (1998, p. 21). Para ele, a apreensão da gênese histórica das relações sociais só é possível se, ao invés de entrar, o historiador "sair" da cidade. Como educadores, que caminhos percorremos para nos aproximar de um pequeno/grande espaço, historicamente datado e situado em um mundo pautado pela lógica da acumulação flexível do capital? Chegando ao Vale do Guaporé a pé, de ônibus ou de avião, cabe-nos apreender os movimentos do real, buscando sua unidade como "síntese de múltiplas determinações" (MARX, 2008, p. 258). Daí que totalidade, contradição e mediação são categorias que nos mobilizam na interpretação das evidências - as quais, de acordo com Thompson, devem ser entendidas como "evidências interrogadas" (1981, p. 50).

Perpassadas as nuvens que escondiam as verdes matas e o céu anil, a janela do voo XYZ revelou-nos a terra devastada do estado de Rondônia, assemelhando-se a uma grande plantação de soja ou de alguma outra commodity do agronegócio. Da poltrona razoavelmente confortável da aeronave, era impossível avistar commodities minerais como cassiterita, estanho, ouro e nióbio, todos eles objetos de ganância dos "homens-de-negócio" que, na contramão das economias e culturas dos povos e comunidades tradicionais, autodeclaram-se proprietários dos meios de produção da vida, dos rios, dos mares e das florestas.

De Cacoal ao Vale do Guaporé são cerca $405 \mathrm{~km}$ de estradas de asfalto e terra, e o que se vê pelo caminho são monoculturas de soja e milho, além de uma infindável quantidade de hectares de pasto. São muitos caminhões transportando madeira, gado e grãos. De Rolim de Moura, município depois de Cacoal, vieram importantes figuras do cenário político nacional, como Valdir Raupp, Expedito Junior, Ivo Cassol, entre outros. Os três foram senadores e tanto Raupp (1994-1998) quanto Cassol (2003-2010) foram governadores de Rondônia. Não seria de se estranhar que em São Miguel do Guaporé, Seringueiras, São Francisco do Oeste e Costa Marques, municípios que compõem o Vale do Guaporé, morem latifundiários importantes que controlam a "economia local", assegurada pelas políticas do planalto federal.

\footnotetext{
5 Estiveram em campo Lia Tiriba, William Kennedy do Amaral Souza e Mauro Sérgio Demício, que também é professor no IFRO e a quem agradecemos a parceria.
} 
Segundo o Instituto Brasileiro de Geografia e Estatística (IBGE), desde o início do século XXI, a economia rondoniense é baseada na agropecuária, destacando-se a produção de soja, gado bovino e peixe, e no extrativismo de madeira, minérios e borracha. De acordo com o IBGE, é o terceiro estado mais rico da Região Norte, sendo responsável por $11 \%$ de seu Produto Interno Bruto (PIB). Em 1982 deixou a condição de território e, sendo um estado recente, apresenta o terceiro maior PIB per capita, a segunda maior taxa de alfabetização, a terceira menor taxa de analfabetismo e o quarto melhor Índice de Desenvolvimento Humano (IDH) dentre os 16 estados das regiões Norte e Nordeste do país. Aparentemente, não se vê "pobreza" de Cacoal ao Vale Guaporé, o que não significa a inexistência das contradições entre trabalho, capital e natureza. Por isso, considerar a expansão do capitalismo na Amazônia é, sem dúvida, uma porta de entrada para ir além da pseudoconcreticidade em que o mundo se apresenta (KOSIK, 1976), ou seja, ir para além da aparência do fenômeno.

O Vale do Guaporé se estende do oeste do estado de Mato Grosso até as proximidades do estado do Amazonas. São $1.342 \mathrm{~km}$ de fronteira, na qual o Rio Guaporé, depois denominado de Mamoré (desde a localidade de Rodrigues Alves), constitui-se como divisa natural entre Brasil e Bolívia. Por ser uma região de difícil acesso, tornou-se uma rota de fuga para os escravos da mineração em Mato Grosso. Confrontando-se com as frentes colonizadoras, diversas comunidades podem ser consideradas multiétnicas, sendo compostas por ribeirinhos(as), pequenos(as) agricultores(as), indígenas brasileiros(as) e bolivianos(as), remanescentes de quilombolas, seringueiros(as) e castanheiros(as).

A região fora visitada, a partir do século XVI, por alguns poucos bandeirantes paulistas e por padres missionários. Devido à preocupação com possíveis invasões espanholas, no século XVIII a Coroa Portuguesa iniciou a ocupação militar no Vale do Guaporé, construindo diversos presídios e seu marco principal: o Forte do Príncipe da Beira, tombado em 1950 pelo Instituto do Patrimônio Histórico e Artístico Nacional (IPHAN), em Costa Marques. Muitos afirmam que mesmo antes da construção do Forte já havia negros(as) aquilombados(as) no Vale do Guaporé e foram eles que receberam Domingo Sambucetti, o engenheiro que projetou o Forte. Gilberto $^{6}$, presidente da Associação Quilombola do Forte (ASQFORT), nos diz que "a primeira moradora foi uma negra que se chamava Ana Moreira e esse perímetro todinho era onde ela morava e tinha as cabanas dela".

Importante momento de expansão capitalista foi a construção da ferrovia MadeiraMamoré, ligando Santo Antônio do Madeira a Vila Bela, na confluência dos rios Beni (Bolívia) com o Mamoré (Brasil). Com 366 km de extensão, a estrada de ferro atraiu mais de 20 mil trabalhadores de 50 nacionalidades diferentes. Outro momento de destaque foi a construção da linha telegráfica de Cuiabá a Santo Antônio do Madeira, quando a Comissão Rondon "encontrou" as ruínas do Real Forte Príncipe da Beira. "Encontrou" é força de expressão, já que os moradores da Comunidade Quilombola do Forte Príncipe da Beira relatam que seus ancestrais sempre estiveram na região e que muitos escravos da construção do Forte foram abandonados à própria sorte após o término da obra e se misturaram aos indígenas da região.

A partir de 1970, colonos(as) migrantes chegaram a Rondônia, impulsionados novamente por políticas governamentais que tinham a intenção de ocupar a região amazônica e torná-la mais atrativa aos olhos do capital e de tirar, das regiões Sul e Sudeste, um contingente de trabalhadores e trabalhadoras que começava a se organizar em busca de terras para seu sustento. Desse modo, ao invés de promover a reforma agrária nos estados do Sul, o que

\footnotetext{
${ }^{6}$ Para preservar a identidade dos(as) entrevistados(as), os nomes são fictícios. Além da questão ética, sabemos com quanta violência são realizadas as disputas por território na Amazônia e a não identificação é um caminho para que trabalhadores(as) evitem as brutalidades.
} 
afetaria a hegemonia capitalista latifundiária, o Estado delineou um fluxo migratório intenso, principalmente das regiões Sul e Sudeste, em direção aos estados de Mato Grosso, Rondônia e Acre, passando a "oferecer" terras para pequenos produtores insatisfeitos.

Na prática, aos trabalhadores e trabalhadoras que chegaram a Rondônia entre 1970 e 1980, coube o trabalho mais pesado: a derrubada da floresta. Entre os anos 1980 até meados dos anos 1990, os(as) sitiantes estavam estabelecidos(as), com seus lotes abertos e plantações ou pastagens formadas. Mas por falta de incentivo do Estado, como boas estradas, escolas do/no campo, assistência técnica, e por serem pressionados por empresários(as) capitalistas, nos anos 2000 os(as) sitiantes começaram a vender ou arrendar suas terras para a produção de commodities do agronegócio.

No que diz respeito à Comunidade do Forte, a partir de 1964, com o regime ditatorial, os militares começaram a hostilizar a população, introduzindo, nos pastos nativos, gado bovino que era criado sem cercamento. Esse gado foi destruindo todas as plantações da comunidade, ocasionando o abandono do lugar por parte de muitos moradores(as). Entre 1970-1980, a comunidade tinha cerca de 2.500 moradores. Segundo Gilberto, hoje são apenas 276, distribuídos entre 74 famílias. Reclamando das atuais condições de vida, sobretudo do relacionamento com o Exército, Gilberto diz que "hoje querem fazer a mesma coisa constrangendo esta comunidade com todos os tipos de humilhação".

A Comunidade Santa Fé é originária de 1870, data de início do primeiro ciclo da borracha, que trouxe levas de migrantes para a região (MONTEIRO, 2013). Pelo Rio Guaporé afora, negros(as) aquilombados(as) já estavam vivendo em consonância com indígenas brasileiros(as) e bolivianos(as) do lugar. Juntando-se a esses, chegaram muitos nordestinos ${ }^{7}$ para a extração do látex da seringueira. Após o declínio da economia da borracha, ocasionado pela produção em seringais cultivados sobretudo na Malásia, os habitantes de Santa Fé voltaram-se para atividades de subsistência: pesca, caça, extrativismo e pequena agricultura. Relembrando outras dificuldades passadas, Dona Soledade disse: "no início de nosso povo aqui em Santa Fé, era um seringal e todo mundo morava longe um do outro. Mas isso não tirava a união do povo, tinha os momentos de união da comunidade". Ela nos ensina que a distância não pode ser um elemento de desagregação das pessoas e é fundamental para povos e comunidades tradicionais o sentido de união. Disse que "se alguém ficava doente o seringal inteiro se movimentava para ajudar. Vinha rezadeira de longe, andando três, quatro dias na mata para ajudar na cura daquela pessoa. Isso mostra que o nosso espírito coletivo sempre foi forte".

No caso dos seringais, para a exploração da floresta, o Estado financiava as atividades por meio do Banco da Amazônia (BASA). Segundo Ramires, presidente da Associação dos Seringueiros do Vale do Guaporé (AGUAPÉ), o fim dos financiamentos decretou a falência dos patrões. Para ele, esse movimento foi linear: "quando o BASA deixou de financiar o patrão, ele não aguentou mais 'tocar' o seringal”. Indagado sobre o motivo de o BASA não financiar mais essa atividade produtiva, Ramires diz que "tinha muito patrão que fazia rolo". Como exemplo, indica que "um seringal tinha 60 seringueiros. Ele ia lá e tirava um financiamento como se tivesse 120 seringueiros. Fazia um rolo lá com o gerente do banco, com o fiscal [...] tinha fiscal que vinha no seringal conferir a produção". Dessa maneira, "muitos patrão pegava o dinheiro do banco e comprava caminhonete nova, construía casa". Com a falta de financiamento, os patrões abandonaram seus "postos de exploração do trabalho alheio".

\footnotetext{
${ }^{7}$ É importante dizermos que, nesse caso específico, somente nordestinos vinham porque a extração de látex era atividade exclusivamente masculina.
} 
Com os seringueiros(as) vivendo sem "patrão", sem saber se conseguiriam ficar em sua "colocação" para cortar seringa, e com a luta por melhores condições de vida e trabalho que ecoava do Acre para outros pontos do Brasil, ganhou força a ideia de criar uma reserva extrativista na região. Para Roberto, a RESEX ${ }^{8}$ é o que ele esperava: "eu já sai daqui e me arrependi, porque fui morar na cidade e aí se tem dinheiro, come. Se não tem dinheiro, não come. Aqui a gente planta uma roça, pesca, caça e vai vivendo".

Em Rondônia, continuam os ataques a áreas de reservas públicas. Trabalhadores(as) com quem conversamos se mostraram preocupados com avanço do capital. Segundo Gomes, da comunidade Santa Fé, o gado da fazenda que faz divisa com a terra quilombola às vezes escapa e invade roças e plantações, causando enorme prejuízo. "Fica a dúvida, né! Será que o gado escapa mesmo ou alguém solta ele em cima de nossa terra?" Na Comunidade Quilombola do Forte, o Exército mantém uma fazenda. Segundo Jaime, "de vez em quando o gado deles escapa destruindo roças nossas. Mas é misteriosamente! Uma cerca que estava boa ontem e hoje amanheceu quebrada, uma porteira que não se sabe como, ficou aberta, tudo é mistério." Isso representa um cerceamento físico, moral e afetivo das comunidades, porque tenta dificultar o processo produtivo delas e tenta quebrar os laços de apego e estima que os trabalhadores e as trabalhadoras têm com sua comunidade.

A RESEX do Rio Cautário ${ }^{9}$ está cercada por fazendas de gado de corte cujos fazendeiros(as) vislumbram o fim da reserva e a possível incorporação das terras da RESEX. Por conta da renda fundiária da terra, o solo é objeto de interesse, mas, sobretudo, o subsolo é a grande atração para o capital. Alguns trabalhadores(as) das comunidades têm noção de que o direito ao uso de suas terras está ameaçado. A previsão de Seu Orlando, um dos moradores mais antigos da Comunidade Quilombola de Santa Fé, é emblemática e, ao mesmo tempo, dramática, pois tem em conta os processos de reprodução ampliada do capital e também os desafios da educação para preservação do território: "Isso aqui vai ser uma grande plantação de soja! Vai ser porque os empresários vão entrar primeiro. Porque aqui está tudo mapeado, o subsolo está mapeado e eles estão de olho. Enquanto tiver resistência eles não entram”.

Como veremos, as mediações do capital exercem forte pressão no cotidiano das comunidades, tencionando as relações sociais que homens e mulheres estabelecem no território. Como contraponto, a afirmação e defesa de modos de vida calcados em culturas do trabalho associado podem ser entendidas como elementos de resistência dos povos e comunidades tradicionais.

\section{CULTURA DO TRABALHO, COMUNIDADE E MODOS DE VIDA}

Definir o conceito de cultura com base na perspectiva marxista demanda esforço no sentido de relacioná-lo com a materialidade dos processos de formação do ser social, o que está umbilicalmente vinculado às relações sociais de produção da existência. É preciso levar em conta as relações históricas que, mediadas pelo trabalho, os seres humanos estabelecem com a natureza e com outros seres humanos, entendidos também como elementos da natureza;

\footnotetext{
${ }^{8}$ No Brasil, a criação de reservas extrativistas pelo Estado brasileiro foi fruto de lutas marcadas, entre outros acontecimentos, pela morte do líder seringueiro Chico Mendes, em 1988, e pela realização da Eco-92, no Rio de Janeiro, em 1992. De acordo com o Cadastro Nacional de Unidades de Conservação (CNUC), existem 95 reservas extrativistas no país. Atualmente são 75 na Amazônia, sendo 25 em Rondônia.

9 A RESEX Rio Cautário foi criada em 8 de agosto de 1995. Lá existem cinco comunidades: Jatobá, Cajueiro, Vitória Régia, Ouro Fino e Laranjal. Sobrevivem da extração da seringa, coleta de castanha-do-brasil, pesca, caça e pequena agricultura, estando os(as) trabalhadores(as) organizados(as) na Associação dos Seringueiros do Vale do Guaporé (AGUAPÉ).
} 
considerar a ação humana que transforma o meio ambiente, modificando-o e modificando-se e, com isso, produzindo cultura. Cultura e modo de vida são conceitos que se complementam.

Por modo de vida compreendemos um conjunto de práticas sociais, econômicas e culturais cotidianas compartilhadas por determinado grupo social no processo de produção da vida material e simbólica. Como expressão da cultura, diz respeito aos costumes, tradições, valores, crenças e saberes que orientam as normas de convivência na vida familiar, no trabalho e em âmbito comunitário. Relaciona-se às maneiras de produzir, consumir e distribuir os frutos do trabalho, tendo em conta as formas de sentir e pensar a vida e o mundo.

Os modos de vida manifestam as relações que homens e mulheres trabalhadores, mediadas pela memória coletiva e por experiências vividas e herdadas, estabelecem com o território em que produzem sua existência. A afirmação de modos de vida, entendidos como patrimônio cultural e, ao mesmo tempo, condição de existência humana, é um elemento de resistência e negação de outros modos de produção da vida social, os quais, de alguma maneira, se entrelaçam em menor ou maior grau, de acordo com as determinações dos contextos históricos de luta por hegemonia.

A identificação de modos de vida pressupõe a compreensão de que, ao trabalhar, produzimos cultura e, ao mesmo tempo, trabalhamos de acordo com determinada cultura. Assim, para os povos e comunidades tradicionais, qual é o objetivo do trabalho? Como trabalham? Para quem trabalham? Quais as formas de associatividade? Que sentidos e valores são atribuídos ao trabalho? Que relação estabelecem com o tempo? A floresta serve apenas como matéria-prima para satisfação das necessidades humanas? Que trabalhos são necessários para tentar garantir a reprodução ampliada da vida? Essas são questões não apenas de ordem econômica, mas também de ordem cultural.

$\mathrm{Na}$ análise histórica, "é essencial manter presente no espírito o fato de os fenômenos sociais e culturais não estarem 'a reboque', seguindo os fenômenos econômicos à distância: eles estão, em seu surgimento, presos na mesma rede de relações" (THOMPSON apud NEGRO; SILVA, 2001, p. 208). Nessa perspectiva, pensamos que o conceito de cultura do trabalho pode contribuir para o entendimento dos nexos existentes entre economia e cultura, bem como sua relação com o modo de vida e, de forma mais ampla, com o modo de produção da existência humana. Sendo construída e transmitida no processo laboral, a cultura do trabalho remete a objetivos, formas e intensidades de dispêndio da força de trabalho, a maneiras de pensar, sentir e se relacionar com o trabalho. Requer compreender a divisão do trabalho e as relações entre tempo de trabalho e tempo livre para lazer/ócio. Em última instância, é determinada pelas formas de propriedade dos meios de produção e pelas relações de produção que as classes e os grupos sociais, historicamente, estabelecem entre si, considerando também o papel dos sistemas simbólicos na vida social e, em especial, os valores morais atribuídos à atividade do trabalho (TIRIBA, 2001).

Mediada pelo trabalho, a relação com a natureza é fundamental, pois a "sobrevivência aqui vem mais da força da natureza" (Jaime, Comunidade Forte Príncipe). Dona Soledade (Comunidade Santa Fé) ressalta que "o rio tem tudo que a gente precisa. É o nosso mercado. O mercado Guaporé". Lucas Ramalho (Santa Fé), que passou três meses em Porto Velho, constata que, "na cidade, para comer uma mandioquinha tem que ter um dinheirinho. Para comer uma banana tem que ter um dinheirinho. Então lá as coisas é só para quem tem. E aqui não, você quer um peixinho, vai ali no rio e pega". Ele ressalta que "onde tem fome é nas cidades porque não se pode plantar nas cidades e tudo precisa ser comprado". 
Referindo-se à Forte Príncipe, Jaime diz que "hoje a nossa comunidade tem um pouco de tudo: tem funcionário público, tem pescador profissional, tem aposentado, tem pescador amador. Tem o trabalho de bico lá fora e aqui na comunidade mesmo". Mas, na grande maioria, os(as) trabalhadores(as) vivem do extrativismo vegetal, tendo a seringa e a castanha-do-brasil como principais produtos, e também do extrativismo animal, por conta da pesca. Fazem agricultura de subsistência produzindo, sobretudo, mandioca, farinha de mandioca, banana, milho, melancia, urucum e abacaxi.

Roberto, extrativista que mora na RESEX do Rio Cautário, desde pequeno trabalha "como seringueiro, como castanheiro, como uma pessoa que vive da mata. Então o jeito que eu falo e as coisas que eu faço, já mostram que eu sou uma pessoa da mata". Buscando distinguir o trabalho assalariado do trabalho coletivo nas comunidades, Roberto acrescenta: "aqui a gente tem um jeito de trabalhar que só funciona aqui. Quem vai trabalhar fora, sente dificuldades, porque é outro tipo de trabalho e outra maneira de se portar". Sobre o trabalho assalariado que se realiza fora da comunidade, Lucas Ramalho (Santa Fé) reclama que trabalhava "de segunda-feira até sábado ao meio-dia. São 5 diárias e meia. Aí o patrão tem que chegar e pagar. Até bem pouco tempo a gente tirava 40 e poucos na diária. Era muito pouco, agora deu uma subida, foi para 60 reais a diária". Gilberto, do Forte, afirma que na comunidade "a gente que faz nosso tempo. É a comunidade que produz o tempo dela [...]. Porque a comunidade ela sabe o que vai fazer, na hora que tem que fazer e como vai fazer". Ainda em relação à cultura do trabalho, Gilberto explica que a diferença entre o trabalho assalariado e o das comunidades tradicionais é que "o quilombola não tem patrão! Ele trabalha pra ele. Ele trabalha para todos nós. Ele trabalha para a comunidade".

Evidenciamos elementos da cultura do trabalho que indicam modos de vida regidos pela cooperação e pela reciprocidade no âmbito da comunidade. Embora nem todos os processos de trabalho sejam coletivos, no sentido de que todos estão trabalhando juntos ao mesmo tempo, as relações de convivência são de solidariedade. Cada um tem sua roça: "É por causa que, um quer plantar milho, outro macaxeira. Aí cada um planta o que quer. Tipo, hoje nós vamos juntar seis pessoas e vamos roçar a roça de fulano. Aí amanhã a gente roça a roça de fulano" (Roberto, RESEX Rio Cautário). Repartir os frutos do trabalho também é algo que faz parte da cotidianidade, tornando um padrão de convivência. Por isso, "cada um pesca para comer, para cada família [mas], se pega muito peixe, muito jaraqui [tipo de peixe], que a família não vai dar conta de comer, ele leva para seu fulano. Então sai distribuindo" (Leila, Comunidade do Forte Príncipe). Sobre a coleta de castanha, ela conta que as equipes são compostas por três pessoas ou mais de famílias diferentes e no final, "aí junta as castanhas na barrica, vende e divide o dinheiro".

$\mathrm{Na}$ perspectiva de fortalecer a coletividade, na Comunidade Forte Príncipe os trabalhadores(as) estão organizando uma associação para "agregar valor à castanha, né, para que todos possam ganhar uma renda boa aqui na comunidade" (Jaime). Na RESEX do Rio Cautário, onde estão organizando uma cooperativa de beneficiamento da castanha, os trabalhadores(as) falam muito em "agregar valor" à castanha: "porque a gente sofre muito com a questão do atravessador. A cooperativa veio pra resolver essa situação. Todo mundo reunido aqui dando valor pra cooperativa, pra agregar valor" (Francisco).

As culturas do trabalho de povos e comunidades tradicionais vão se materializando no cotidiano do trabalho associado, nas relações que os(as) trabalhadores(as) estabelecem entre si - relações essas mediadas pela questão de classe, raça, etnia e gênero (TIRIBA; SANTANA, 2017). Podem ser caracterizadas tendo como base a ideia de que "o trabalho de produzir a vida associativamente requer a produção de modos particulares de ser, conhecer e estar no mundo" (TIRIBA; FISCHER, 2015, p. 417). Um de seus fios diz respeito à religiosidade e, portanto, à 
cultura desses povos. Jaime diz que "Deus faz as coisas bem perfeita porque quando é tempo de defeso do peixe, a castanha está produzindo. Depois que acaba a castanha, já liberou o peixe, e quando chega o verão é a temporada de roça". O espaço da religiosidade também é um espaço de trocas e prestações, assim, trabalhar nas tarefas da Festa do Divino é algo tido como grandioso, e para muitos é essencial para manter o bem-estar do ano todo e a luta para garantir seu estar no mundo. Embora seja evangélica, Dona Esmeralda (Santa Fé) também participa da organização da festa da igreja católica, oferecendo comida aos devotos. Segundo ela, "não importa se é minha religião. Importa que está acontecendo alguma coisa boa na minha comunidade e por isso eu tenho que ajudar".

Concebendo a história como "processo estruturado", em sua obra Costumes em comum Thompson (1998) analisa as práticas culturais como parte integrante da "economia moral das multidões", em defesa de um modo de vida que se contrapõe ao modo de vida capitalista. Para ele, "os valores, tanto quanto as necessidades materiais, são sempre um terreno de contradição, de luta entre valores e visões-de-vida alternativos" (THOMPSON, 1981, p. 194). Nesse sentido, a cultura e, em particular, a cultura do trabalho, não se situa em um campo de consenso, mas de conflito. Nessa trilha, Gilberto afirma: "a gente tem que valorizar isso que é da nossa comunidade, é a nossa comunidade que precisa disso, bater o pé e dizer olha, isso é o nosso trabalho, a gente vive disso e nós queremos que seja assim".

Afirmando o modo de vida nas comunidades da RESEX Rio Cautário, os olhos de Renato brilham ao dizer:

Nós extrativistas, nós seringueiros, queremos viver da maneira que vivemos. Claro que queremos ter melhorias, mas não queremos sair daqui e ir morar na cidade. [Também] não queremos viver aqui como empregados de fazenda. Vamos supor que aqui tivesse acabado o seringal e não tivesse virado RESEX, tivesse virado uma fazenda. Muitos não iam querem viver aqui. A gente ia procurar outro seringal, outra Reserva.

A opção por determinado modo de vida, em detrimento de outro, denota uma espécie de bom senso, adquirido pela experiência do trabalho de produzir a vida de forma associativa e solidária. No entanto, como veremos a seguir, além de negar os saberes tradicionais, os processos educativos escolares negam também os modos de vida dos povos e comunidades tradicionais.

\section{EXPERIÊNCIA, SABERES TRADICIONAIS E EDUCAÇÃO ESCOLAR}

Para Toledo e Barrera-Bassols, ao contrário do conhecimento que se baseia em teorias, postulados e leis que se pretendem universais, a sabedoria popular "baseia-se na experiência concreta e em crenças compartilhadas pelos indivíduos acerca do mundo que os rodeia, sendo mantida e fortalecida mediante testemunhos" (2015, p. 130). Para eles, "tanto os valores como os fatos conformam a unidade de experiência do indivíduo", não existindo separação entre mente e matéria: "a intuição, as emoções, os valores morais e éticos se encontram embebidos na forma de ver as coisas". Em outras palavras, "a natureza e a cultura formam parte do mesmo mundo; os fatos e os valores se conectam na forma de ver as coisas" (TOLEDO; BARRERA-BASSOLS, 2015, p. 131).

Leila, que mora na Comunidade do Forte Príncipe, conta que "a gente utiliza a natureza praticamente todos os dias da nossa vida, para tudo: para algum remédio que a gente acaba tendo conhecimento e para o alimento da comunidade". Para ela, sem natureza não haveria a vida. "Antes de ontem mesmo, a gente foi bem aqui pertinho para pegar a casca e o leite da 'súcuba' para corrigir quebradura [fratura no osso], e também é bom para mioma no útero”. Almeida, 
também do Forte Príncipe, tenta corrigir Leila. Fala que bom mesmo "para inflamação de útero é o umbigo da castanha". Para Jaime, o melhor mesmo não é o umbigo da castanha: "para inflamação é casca da castanheira ou casca da faveira".

No dia a dia da comunidade, a castanha parece ser mesmo milagrosa, proporcionando muitos benefícios para a saúde! Mesmo desconhecendo que se trata da Bertholletia excelsa, popularmente conhecida como castanha-do-pará ou castanha-do-brasil, Leila conta que, para gastrite, sua avó "tomou por muito tempo a casca da castanheira e ficou boa". De conversa em conversa sobre saberes tradicionais, Leila nos ensina: "folha de jambu com gengibre e alfavaca, que é muito bom para a garganta"; em vez de ir a Costa Marques comprar um xarope caro, "que nem todo mundo da comunidade tem condições, então a comunidade faz um xarope aqui mesmo e pronto". Almeida nos ensina a receita de um "lambedor natural, com casca de jatobá, casca do angico, gengibre, mel, que vai tudo no fogo e fica bom. [...] Minha avó dizia 'toma o lambedor e vai tomar banho para amadurecer o catarro'. Enquanto o catarro não ficar bem amarelo ele não consegue sair. Então tinha que tomar o lambedor e [em seguida] tomar banho para amadurecer".

Não é novidade dizer que na Amazônia "o saber tradicional é constantemente taxado como não merecedor de credibilidade", mas "é exatamente ele que ainda salva vidas no interior da região e mesmo nas periferias amazônicas. É também com base nele que grandes laboratórios desenvolvem suas pesquisas sobre novos medicamentos e produtos" (MARQUES, 2019, p. 283).

Não por acaso, Gilberto (Forte Príncipe) conta que "hoje vêm pessoas de fora buscar conhecimento aqui, para fazer tratamento para o câncer. Vêm buscar aqui algumas ervas, algumas cascas para fazer o tratamento lá fora. Então essa sabedoria popular é magnífica, nos livra de muita coisa". No entanto, todo cuidado é pouco para não valorizar o chamado "capital natural", uma vez que as empresas transnacionais, utilizando-se da biopirataria ou biogrilagem, transformam os saberes tradicionais em mercadoria (DEL NERO, 2008).

Por ser a Amazônia fonte de riqueza, grandes indústrias farmacêuticas e de beleza instalam seus laboratórios de pesquisa exatamente no coração da floresta. No mercado Ver o Peso, em Belém, e em outros mercados populares, os turistas ficam impressionados com a quantidade de ervas, raízes, cascas de árvores e outros elementos da natureza que se transformam em remédios e perfumaria. Na perspectiva do capital e com o argumento de "gerar emprego e dar cidadania" aos pobres, as mulheres recebem cursinhos de "empreendedorismo feminino", tendo seus saberes valorizados e, portanto, certificados. Por exemplo, os óleos essenciais e os perfumes de priprioca, cujas fibras e rizomas também são utilizados no artesanato, tornaram-se coqueluche no mercado.

Referindo-se às relações entre experiência e educação, Thompson (1981) enfatiza que não é possível desprezar os conhecimentos produzidos fora dos procedimentos acadêmicos, afinal são eles que ajudam "homens e mulheres a trabalhar nos campos, a construir casas, a manter complicadas organizações sociais e, mesmo ocasionalmente, a questionar eficazmente as conclusões do pensamento acadêmico" (THOMPSON, 1981, p. 17). Mas, diferentemente da perspectiva de reprodução ampliada do capital, que promove o saque e a degradação da Amazônia, os povos e comunidades tradicionais sabem que a floresta é local cujos segredos devem ser desvendados. Mediadas pelo trabalho, as relações entre ser humano e natureza são de respeito e cumplicidade. Para Jaime, da Comunidade Forte Príncipe,

tem um monte de remédio na mata e é na mata que a gente tira a nossa comida também. Mas precisamos respeitar a mata, não pode entrar de qualquer jeito e ir tirando as coisas. A mata é vida e precisa ser respeitada. Faz parte da nossa educação, da nossa moral, do nosso caráter respeitar tudo e todos. 
Os povos tradicionais sabem da importância de seus saberes, herdados e construídos na vida cotidiana. Jaime acredita que a natureza se cuida, mas também precisa ser cuidada: "a gente sabe também que não pode tirar a casca toda da planta, senão ela morre". Leila tenta nos explicar dizendo que os moradores de Forte Príncipe costumam tirar a casca de um pé de jatobá, "lá perto da pista, só porque ele ficava muito perto da comunidade. Então paramos um período para ele não se acabar". Perguntada sobre o que ensinaria a seus netos, Dona Soledade, da Comunidade Santa Fé, responde: "ensinar a trabalhar, a plantar, a cuidar da terra, criar muita galinha. Porque aqui as coisas dão, a terra produz. Se trabalhar, a terra não falta com a gente". Em síntese, para Ramires, presidente da AGUAPÉ, "tudo o que a gente faz para viver é aproveitar o meio ambiente sem machucar, sem agredir ele".

Não apenas em Rondônia, mas também nas demais regiões da Amazônia, sem a sabedoria popular não haveria vida. Para os pescadores(as) de Cametá, no Baixo Tocantins (Pará), na sabedoria popular estão contidos os saberes sociais, ou seja, aqueles construídos coletivamente no processo de trabalho, provenientes das práticas organizativas dos trabalhadores(as), "permitindo ao grupo social que os detém a inserção em determinadas relações econômicas, políticas e culturais, de modo que ele participe, integre-se e/ou oponha-se, resista e lute no contexto dessas relações, com o objetivo de uma nova hegemonia" (RODRIGUES, 2012, p. 80-81).

Fazendo valer seus saberes sociais, é ainda Ramires, da AGUAPÉ, quem nos ensina que, se os extrativistas não tivessem organizados,

os fazendeiros já teriam derrubado tudo isso aqui e plantado pasto. Porque se não tivesse os seringueiros, aí teria só os índios para proteger a mata, a floresta. E as pessoas assim, de uma maneira geral, não querem respeitar os índios. Então nós somos uma força a mais, junto com os índios. Porque os fazendeiros sabem que se quiserem fazer isso aqui de pasto, vão ter que tirar nós daqui.

Thompson (1981) compreende que a experiência se constitui como "a resposta mental e emocional, seja de um indivíduo, seja de um grupo social, a muitos acontecimentos inter-relacionados ou a muitas repetições do mesmo tipo de acontecimento" (THOMPSON, 1981, p. 15), no entanto, "a experiência é válida e efetiva, dentro de determinados limites: o agricultor conhece as suas estações, o marinheiro conhece seus mares, mas ambos permanecem mistificados em relação à monarquia e à cosmologia" (THOMPSON, 1981, p. 16). Nesse sentido, acreditamos que a educação básica pode se constituir em espaço/tempo no qual crianças, jovens e adultos possam refletir sobre suas experiências herdadas e vividas, transformando-as em experiências percebidas e modificadas.

Os fundamentos filosóficos, econômicos, culturais e ambientais que substanciam os modos de vida de povos e comunidades tradicionais poderiam se constituir como fundamentos pedagógicos da educação escolar. No entanto, para a população do Vale do Guaporé, a escola parece não ajudar na afirmação dos modos de vida. Ramires diz que "os nossos filhos vão para a escola, para a faculdade. Eles aprendem muita coisa lá, mas geralmente são coisas que não têm muito a ver com o nosso dia a dia". Para ele, a escola acaba contribuindo para o êxodo rural, pois as pessoas "acabam estudando coisas para usar em outro lugar, em outro emprego". E quando os(as) professores(as) tentam fazer algo diferente, acabam sendo reprimidos(as). Para Gilberto "a escola tem uma importância muito grande [...], mas o grande desafio é que quem está lá em cima nem sempre aceita o conteúdo que eles vão dar. [...] muitas vezes são questionados por que estão ensinando alguma coisa da comunidade quilombola". E aí, as pessoas perguntam: "Ih... vocês vão falar de quilombola de novo? Vocês vão falar da cultura africana da comunidade de novo?" 
No caso de Forte Príncipe da Beira, o desejo é que a escola se torne pedagogicamente articulada ao modo de vida da comunidade. Almeida fala que "as pessoas de fora dizem que a comunidade quilombola lá do Forte é bem assistida, [pois] o exército dá médico, dá proteção", mas o fato é que "não acontece exatamente no dia a dia". São muitas as tensões, sobretudo depois que, de forma desavisada e repentina, a escola foi anexada ao território do batalhão do exército. Por isso, manifestam a vontade de criar nova escola na comunidade: "a gente tem esperança de que nós vamos ter uma educação quilombola, de que aquelas diretrizes da educação quilombola sejam aplicadas à comunidade" (Gilberto, da Comunidade Forte Príncipe da Beira).

Em Santa Fé, percebe-se o desejo de construir uma escola na comunidade, evitando que as crianças sejam deslocadas para a cidade de Costa Marques. Dona Esmeralda diz que "as crianças passam metade do dia frequentando a escola lá na cidade. Elas voltam com a cabeça de quem mora na cidade". Para Gomes, "a escola na e da comunidade é um fortalecimento da própria comunidade".

A sabedoria popular também se manifesta na preocupação com a educação das crianças e dos jovens, no sentido de que possam dar continuidade às tradições e aos costumes da comunidade. Perguntada se "a garotada" vai querer dar continuidade ao modo de vida quilombola, Dona Esmeralda, da Comunidade Santa Fé, tentando ser realista, responde: "a juventude não! Mas quando vai chegando a velhice, 'e os janeiros vão chegando', a pessoa começa a ver as coisas, vai ficando mais tranquila. Ela vai querer um lugar pra plantar uma mandioca, uma banana, uma abóbora, um quiabo, maxixe e todas essas coisas". Olhando para o passado e lembrando-se de sua juventude, sorri e diz: "quando a gente era novo também era assim mesmo!" Também preocupado com o futuro dos filhos em relação à preservação das comunidades que se situam no interior da RESEX Rio Cautário, Ramires diz a eles:

Se quiser ir morar na cidade vai, pode ir! Mas nunca renegue o seu passado e sua família extrativista. Porque o cara que saiu da Reserva tem que saber que na Reserva está a raiz dele. A árvore não é assim? A última folha, aquela que está mais no alto, sabe que depende da raiz para ela poder estar lá. Porque sem raiz, a árvore não para em pé. É assim que a vida segue, a gente vai ensinando e aprendendo, ensinando e aprendendo.

Por isso, mais do que nunca precisamos reconhecer a sabedoria popular. É ela que, ancorada na experiência, faz com que homens e mulheres de povos e comunidades tradicionais resolvam os dilemas de seu cotidiano.

\section{CONCLUSÃO (OU, PARA PROSSEGUIR VIAGEM)}

Lia: me diz uma coisa: qual o tamanho do terreno aqui da senhora?

Dona Ermínia: como assim, o terreno?

Lia: até onde a senhora pode plantar flores, cuidar da terra, fazer uma hortinha? Qual o limite?

Dona Ermínia: não tem limite. A gente vai até onde a gente quer, a gente que decide. (Diálogo na RESEX do Rio Cautário).

Refletir sobre a materialidade dos processos de produção da existência requer considerar que para viver e "fazer história", os seres humanos precisam "antes de tudo comer, beber, ter habitação, vestir-se [...]". (MARX; ENGELS, 2007, p. 33). Os depoimentos indicam que, embora tendo de vender sua força de trabalho para satisfazer algumas necessidades, a sociabilidade de homens e mulheres se constrói pelo espírito de coletividade, na perspectiva de 
garantir a reprodução ampliada da vida. As culturas do trabalho, consideradas em sua diversidade de classe, gênero, raça/etnia e geração são pautadas pelo desenvolvimento crescente de cada um, como parte integrante da comunidade. Com todos os encantos da cidade e do "mundo lá fora", o fato é que parecem felizes com a vida comunitária e, portanto, de lá não querem sair: "porque a gente foi criado e gosta de viver assim, cortando seringa, catando castanha, pescando, plantando uma roça, essas coisas que a gente faz" (Renato). Para a esperança de Dona Esmeralda, os “janeiros vão chegando", e os jovens que se vão da comunidade certamente irão querer voltar.

Como diria Thompson (1981), no cotidiano de vida e trabalho vão se tecendo as relações entre economia e cultura. Afinal, os valores

são vividos, e surgem dentro do mesmo vínculo com a vida material e as relações materiais em que surgem nossas ideias. São as normas, regras, expectativas etc. necessárias e apreendidas (e "aprendidas" no sentimento) no "habitus" de viver; e aprendidas em primeiro lugar, na família, no trabalho e na comunidade imediata. Sem esse aprendizado a vida social não poderia ser mantida e toda produção cessaria (THOMPSON, 1981, p. 194).

Sem desconsiderar as mediações do capital, em especial da sociedade urbano-industrial, que interferem sobremaneira na vida cotidiana de homens e mulheres, podemos dizer que nas comunidades tradicionais a organização social se funda, hegemonicamente, em relações sociais não capitalistas de produção da existência humana. As relações de convivência no trabalho e em âmbito comunitário se distinguem do modo capitalista de produção da existência, e os processos educativos de formação de trabalhadores e trabalhadoras se constituem em meio à contradição vital entre a sociabilidade do capital e a de formas econômico-culturais de valorização de relações entre seres humanos e natureza, mediadas pelo trabalho de produzir a vida de forma associativa e solidária.

Os saberes da experiência do trabalho associado, que se constituem como elementos de construção e afirmação de identidades coletivas, convidam-nos a vislumbrar políticas públicas que estimulem práticas econômicas e culturais comprometidas com a preservação de formas não capitalistas de produção da vida social que, ainda hoje, persistem ao longo da história. Mas, como afirmou Bolsonaro em sua campanha para presidente, em seu governo não haveria "mais nenhum centímetro de terra para os indígenas", promessa essa que vem sendo cumprida a ferro e a fogo.

Como assinalava Luxemburgo, "o capitalismo aparece e se desenvolve historicamente num meio social não capitalista" (1970, p. 317). Para a própria existência e realização, o capitalismo necessita "estar cercado de formas de produção não capitalista", visando a sua desintegração e dissolução contínua. Referindo-se a outubro de 2018, Marques (2019) assinala que

\footnotetext{
Na Floresta Nacional de Carajás, no Pará, uma máquina recuperadora-empilhadeira trabalha no carregamento de minérios de ferro. Ela tem 35 metros de altura e suas engrenagens alcançam 50 metros de largura [...] Em outro ponto da Amazônia, uma tribo indígena caminha em meio à floresta sem nunca ter sido contatada pela “civilização" (MARQUES 2019, p. 37).
}

Com o apogeu do neoliberalismo, à custa da exploração da força de trabalho e da espoliação das forças da natureza, os homens de negócio têm nos levado à globalização da barbárie, com a pobreza se alastrando, o aumento das taxas de desemprego e subemprego, a exclusão social disseminada, além da criminalidade dominando progressivamente todos os 
setores da atividade humana. No caso da Amazônia, a barbárie tem-se feito possível graças à invasão, pelo capital, das fronteiras dos territórios dos povos e comunidades tradicionais. Como nos assegura Ioris, "a formação de fronteiras tem sido um componente fundamental da evolução e renovação do capitalismo, não apenas por causa da conquista de territórios e recursos, mas devido às interações estratégicas entre antigas e novas áreas” (2018, p. 105).

Acreditando na capacidade de luta e resistência e nas determinações da "agência humana", a história desses povos nos ajuda a "renovar nossa percepção da gama de possibilidades implícitas no ser humano" (THOMPSON, 1998, p. 23). Na perspectiva de uma história global do trabalho (VAN DER LINDEN, 2013), poderia também nos ajudar a perceber os atuais processos de autogestão comunal (NASCIMENTO, 2019) na América Latina. E, dessa maneira, atualizar a afirmação de Mariátegui quanto aos chamados povos de cultura "atrasada" e de economia "rudimentar" que, apesar da "feudalidade espanhola e crioula" (e da acumulação flexível do capital, no século XXI), conservam o ideário das terras comunais que pertencem ao conjunto das famílias, cultivam relações econômico-culturais calcadas no espírito coletivista, preservando tradições de solidariedade, transformando-se numa das bases mais sólidas da sociedade coletivista, enfim, "a expressão empírica de um espírito comunista" (MARIÁTEGUI, 2011, p. 140).

Conceber a história como "processo estruturado que, embora sujeito a determinadas pressões, continua aberto e só parcialmente determinado" (THOMPSON, 1981, p. 12) possibilita compreender que o capitalismo tem hegemonia em relação a outros modos de produção da existência humana, entre eles o de economias e culturas milenares que perduram na África, Ásia e América Latina. Investigar a "história vista de baixo" possibilita-nos evidenciar que a luta de classes é sempre uma luta por valores e que, no processo de fazer-se classe trabalhadora, entendida como formação econômica e cultural, a experiência "surge porque homens e mulheres (e não apenas filósofos) são racionais e refletem sobre o que acontece a eles e ao seu mundo" (THOMPSON, 1981, p. 16).

A pesquisa empírica evidencia que, em Rondônia, homens e mulheres que vivem nas comunidades tradicionais sofrem sobremaneira com as ações destrutivas do capital. Evidencia também que a afirmação de seus modos de vida se constitui como elemento de estruturação de sua identidade e de resistência frente às dificuldades da vida, sendo condição para sua existência, a qual não pode ser pautada pela lógica dos processos de sociabilidade do capital. Esses modos de vida são tecidos nos interstícios nas relações entre trabalho-educação, economia e cultura, mediados pelos "saberes sociais" (RODRIGUES, 2012) que tornam possível a vida desses(as) trabalhadores(as) em um lugar fortemente marcado pelas contradições entre trabalho e capital.

\section{REFERÊNCIAS}

BRASIL. Decreto 6.040 de 7 de fevereiro de 2007. Institui a Política Nacional de Desenvolvimento Sustentável dos Povos e Comunidades Tradicionais. Disponível em: http:// www.planalto.gov.br/ccivil_03/_ato2007-2010/2007/decreto/d6040.htm. Acesso em: 26 jul. 2019.

BRASIL. MINISTÉRIO DO MEIO AMBIENTE. Cadastro Nacional de Unidades de Conservação. Disponível em: http://www.mma.gov.br/areas-protegidas/cadastro-nacional-deucs. Acesso em: 22 jul. 2019.

CANCLINI, Nestor Garcia. Culturas híbridas: estratégias para entrar e sair da Modernidade. São Paulo: Editora da USP, 1998. 
CRUZ, Valter do Carmo. Povos e comunidades tradicionais. In: CALDART et al. Dicionário da educação do campo. Rio de Janeiro; São Paulo: Escola Politécnica de Saúde Joaquim Venâncio; Expressão Popular, 2012.

DARDOT, Pierre; LAVAL, Christian. Comum: ensaio sobre a revolução no século XXI. São Paulo: Boitempo, 2017.

DEL NERO, Patrícia Aurélia. Biotecnologia: análise crítica do marco jurídico regulatório. São Paulo: Revista dos Tribunais, 2008. p. 139.

FEARNSIDE, Philip Martin. Amazônia e o Aquecimento Global: 1 - Resumo da Série. Amazônia Real, 22 nov. 2018. Disponível em: https://amazoniareal.com.br/amazonia-e-oaquecimento-global-1-resumo-da-serie. Acesso em 20 jul. 2019.

HARVEY, David. 17 Contradições e o fim do capitalismo. São Paulo: Boitempo, 2016.

HOBSBAWM, Eric John. Introdução. In: MARX, Karl. Formações econômicas pré-capitalistas. São Paulo: Paz e Terra, 1991.

IORIS, Antonio A.R. The Production of poverty and the poverty of production in the Amazon: Reflections from those at the sharp end of development. Capitalism Nature Socialism, v. 26, n. 4, p. 176-192, 2015. Disponível em: http://dx.doi.org/10.1080/10455752.2015.105883. Acesso em: 17 dez. 2020.

-106, jul. 2018.

. Amazon's dead ends: Frontier-making the centre. Political Geography, v. 65, p. 98-

KOSIK, Karel. Dialética do concreto. Rio de Janeiro: Paz e Terra, 1976.

LUXEMBURGO, Rosa. A acumulação do capital. Rio de Janeiro: Zahar, 1970.

MARIÁTEGUI, José Carlos. Por um socialismo indo-americano. Rio de Janeiro: Editora da UFRJ, 2011.

MARQUES, Gilberto de Souza. Amazônia: riqueza, degradação e saque. São Paulo: Expressão Popular, 2019.

MARX, Karl. Contribuição à crítica da economia política. Tradução e Introdução de Florestan Fernandes. São Paulo: Expressão Popular, 2008.

MARX, Karl; ENGELS, Friedrich. A ideologia alemã. São Paulo: Boitempo, 2007.

MONTEIRO, Lucineide Rodrigues. Cultura e Territorialidade Quilombola nas Comunidades de Forte Príncipe da Beira \& de Santa Fé. Dissertação (Mestrado em Letras) - Programa de Pós-Graduação em Letras. Universidade Federal de Rondônia, Porto Velho, 2013.

NASCIMENTO, Claudio. Autogestão comunal. Marília: Lutas Anticapital, 2019.

OBSERVATÓRIO DO CLIMA. Desmatamento cresce 36\% no período eleitoral. Disponível em: http://www.observatoriodoclima.eco.br/desmatamento-cresce-36-no-periodo-eleitoral/. Acesso em: 15 jul. 2019.

RODRIGUES, Doriedson do Socorro. Saberes sociais e luta de classes: um estudo a partir da colônia de pescadores artesanais Z-16 - Cametá/Pará. 2012. Tese (Doutorado em Educação) - Programa de Pós-Graduação em Educação, Universidade Federal do Pará, Belém, 2012.

ROSSET, Peter. La guerra por la tierra y el territorio. Revista NERA, jun. 2009. Disponível em: www.fct.unesp.br/nera 1. Acesso em; 17 dez. 2020. 
SOLANO, Henry C.; LAZARINI, Valéria M. Economía Comunitaria. In: CATTANI, Antônio David; CORAGGIO, José Luis; LAVILLE, Jean-Louis. (Org.). Dicionário de la otra economía: lecturas sobre economía social. Buenos Aires: Altamira, 2009. v. 1, p. 121-133.

SOUZA, William Kennedy do Amaral. Trabalho-educação, economia e cultura em povos e comunidades tradicionais no Vale do Guaporé. Projeto de pesquisa. Departamento de Pesquisa do Instituto Federal de Rondônia, Colorado do Oeste, 2018.

TIRIBA, Lia. Economia popular e cultura do trabalho: pedagogia(s) da produção associada. Ijui: Unijui, 2001.

Trabalho-educação, economia e cultura: entre a reprodução ampliada da vida e a reprodução ampliada do capital. Projeto de pesquisa. Faculdade de Educação da Universidade Federal Fluminense, Niterói, 2018.

TIRIBA, Lia; FISCHER, Maria Clara B. Espaços/tempos milenares dos povos e comunidades tradicionais: notas de pesquisa sobre economia, cultura e produção de saberes. Revista de Educação Pública, Cuiabá, v. 24, n. 56, p. 405-428, 2015.

TIRIBA, Lia; SANTANA, Fernanda. Do diário de campo: conversas com pescadoras/es do pantanal mato-grossense sobre cultura do trabalho. Trabalho \& Educação, Belo Horizonte, v. 26, n. 2, maio-ago., p. 65-84, 2017.

THOMPSON, Edward Palmer. Costumes em comum: estudos sobre a cultura popular tradicional. São Paulo: Companhia das Letras, 1998.

. Folclore, antropologia e história social. In: NEGRO, Antônio Luigi; SILVA, Sérgio (Orgs.). As peculiaridades dos ingleses e outros artigos. Campinas: Editora da Unicamp, 2001.

A miséria da teoria ou um planetário de erros: uma crítica ao pensamento de Althusser. Rio de Janeiro: Zahar, 1981.

TOLEDO, Víctor; BARRERA-BASSOLS, Narciso. Memória biocultural: a importância ecológica das sabedorias tradicionais. São Paulo: Expressão Popular, 2015.

VAN DER LINDEN, Marcel. Trabalhadores do mundo. Ensaios para uma história global do trabalho. Campinas: Editora da Unicamp, 2013.

WILLIAMS, Raymond. Cultura e materialismo. São Paulo: Editora da Unesp, 2011.

Recebido em: 29/07/2020

Aceito para publicação em: 30/11/2020 